\title{
Observações sobre a germinação de Struthanthus marginatus (Desr.) G.Don
}

\section{(Loranthaceae)}

\author{
Comments on the germination of Struthanthus marginatus (Desr.) G.Don (Loranthaceae) \\ Comentarios sobre la germinación de Struthanthus marginatus (Desr.) G.Don (Loranthaceae)
}

Recebido: 23/03/2021 | Revisado: 02/04/2021 | Aceito: 05/04/2021 | Publicado: 16/04/2021

Lucas de Andrade Santos

ORCID: https://orcid.org/0000-0002-0578-3783

Universidade Estadual do Sudoeste da Bahia, Brasil E-mail: lucas_andrade_santos2011@hotmail.com

Claudenir Simões Caires

ORCID: https://orcid.org/0000-0002-2012-5164

Universidade Estadual do Sudoeste da Bahia, Brasil E-mail: claudenir.caires@uesb.edu.br

\begin{abstract}
Resumo
O gênero Struthanthus Mart. compreende ervas-de-passarinho conhecidas por suas características daninhas, cuja germinação ocorre sobre os ramos dos seus hospedeiros. O presente trabalho objetivou-se a analisar a geminação de $S$. marginatus (Desr.) G.Don sobre Poincianella pluviosa (DC.) L.P.Queiroz (Fabaceae) crescendo na arborização do campus de Vitória da Conquista da Universidade Estadual do Sudoeste da Bahia. Os frutos foram avaliados quanto às dimensões $(n=10)$, teor de umidade $(n=50)$, fixados na hospedeira pela viscina $(n=60)$ e acompanhados de 31 de agosto a 06 de novembro de 2018. Os diásporos apresentaram-se com 0,75-0,90 $\times 0,41-0,61 \mathrm{~cm}$, umidade de 58,01\% na semente e $48,79 \%$ no pericarpo. Nas 30 primeiras sementes, a germinação iniciou-se no $16^{\circ}$ dia, com pico no $20^{\circ}$ dia. Destas, $40 \%(\mathrm{n}=12)$ germinaram, uma $(3 \%)$ formou plântula no $34^{\circ}$ dia, morrendo no $48^{\circ}$ dia. No plantio seguinte $(\mathrm{n}=30), 11$ germinaram no $3^{\circ}$ dia, com pico no $6^{\circ}$ dia, sete formaram plântula até o $20^{\circ}$ dia, morrendo no $35^{\circ}$ dia. Nossas observações mostram baixa taxa germinativa para $S$. marginatus.
\end{abstract}

Palavras-chave: Ervas-de-passarinho; Desenvolvimento; Hospedeiro.

\begin{abstract}
The genus Struthanthus Mart. are mistletoes known for their harmful characteristics and its germination occurs on the branches of its hosts. The present work aimed to analyze the germination of S. marginatus (Desr.) G.Don on Poincianella pluviosa (DC.) L.P.Queiroz (Fabaceae) growing in the afforestation of the campus of Vitória da Conquista of the Universidade Estadual do Sudoeste da Bahia. Fruits were evaluated for dimensions $(n=10)$, moisture content $(n=50)$, and fixed to the host by viscine $(n=60)$, and accompanied from August 31 to November 06,2018 . The diaspores were $0.75-0.90 \times 0.41-0.61 \mathrm{~cm}$, with humidity of $58.01 \%$ in the seed and $48.79 \%$ in the pericarp. In the 30 seeds, the germination started on the $16^{\text {th }}$ day, with a peak on the $20^{\text {th }}$ day. Of these, $40 \%(n=12)$ germinated, one $(3 \%)$ formed a seedling on the $34^{\text {th }}$ day, dying on the $48^{\text {th }}$. In the next planting $(n=30), 11$ germinated on the $3^{\text {rd }}$ day, peaking on the $6^{\text {th }}$ day, seven formed seedling until the $20^{\text {th }}$ day, dying on the $35^{\text {th }}$. Our observations show a low germination rate for $S$. marginatus.
\end{abstract}

Keywords: Development; Host; Mistletoes.

\section{Resumen}

El género Struthanthus Mart. son muérdagos conocidas por sus características de malas hierbas, cuya germinación ocurre en las ramas de sus huéspedes. El presente trabajo tuvo como objetivo analizar la germinación de $S$. marginatus (Desr.) G.Don en Poincianella pluviosa (DC.) L.P.Queiroz (Fabaceae) que crece en la forestación del campus Vitória da Conquista de la Universidade Estadual do Sudoeste da Bahia. Los frutos fueran evaluados encuanto a dimensiones $(n=10)$, contenido de humedad $(n=50)$, fijados en el hospedador por viscina $(n=60)$ y acompañados del 31 de agosto al 6 de noviembre de 2018. Las diásporas fueron $0.75-0.90 \times 0.41-0.61 \mathrm{~cm}$, con humedad de $58.01 \%$ en la semilla y $48.79 \%$ en el pericarpio. En las primeras 30 semillas, la germinación comenzó el día 16, con un pico en el día 20. De estos, el 40\% ( $n=12)$ germinó, uno $(3 \%)$ formó una plántula en el día 34 y murió en el día 48. En la siguiente siembra $(\mathrm{n}=30), 11$ germinaron en el tercer día, alcanzando su punto máximo en el sexto día, siete formaron plántulas hasta el día 20, muriendo el día 35. Nuestras observaciones muestran una baja tasa de germinación de S. marginatus.

Palabras clave: Desarollo; Hospedadores; Muérdagos. 


\section{Introdução}

Struthanthus marginatus (Desr.) G.Don é uma espécie de planta hemiparasita pertencente à família Loranthaceae, com ampla distribuição no território brasileiro (Caires \& Dettke, 2020), popularmente conhecida como erva-de-passarinho, que ataca plantas lenhosas através de um órgão chamado haustório, o qual penetra no caule da hospedeira até os tecidos vasculares por onde obtém os nutrientes (água e minerais) para a sua sobrevivência (Auer, 1996).

Essas plantas têm suas sementes dispersas pelas aves das seguintes formas: a primeira é por meio da limpeza do bico após a alimentação, a qual não consome as sementes, ficando essa presa ao bico; a segunda, após a ingestão, a ave regurgita a semente; a terceira possibilidade de dispersão ocorre através do consumo e da sua posterior excreção (Rotta, 2001; Cazetta \& Galetti, 2003; Nunes-de-Almeida \& Avalos, 2016).

A adesão da semente ao ramo é facilitada pela presença de uma camada aderente nomeada viscina (Azevedo et al., 2018). A viscina além de fixar a semente no hospedeiro, tem também a função de absorver a água da chuva, orvalho ou vapor, portanto, a fixação com viscina torna-se um elemento primordial para a germinação dessas sementes (Venturelli, 1980).

Struthanthus marginatus apresenta frutos com endosperma clorofilado. $\mathrm{O}$ embrião encontra-se posicionado com seu haustório na porção proximal, sendo seguido pelo hipocótilo e as plúmulas em direção à porção distal. Os frutos imaturos apresentam-se verdes e com a progressão do amadurecimento, tornam-se alaranjados e no estágio final, pretos (Azevedo et al., 2018) (Figura 1A-B).

A dispersão das sementes nas ervas-de-passarinho ocorre predominantemente a uma curta distância. Isso implica que a dispersão dessas espécies ocorre dentro da mesma planta hospedeira ou plantas vizinhas (Aukema \& Martínez-del-Rio, 2002) e, em menor intensidade, em distâncias maiores. Isso significa que uma infestação tende a se agravar (no mesmo hospedeiro ou plantas vizinhas) caso não se tenha práticas de manejo, como por exemplo, a poda de ramos infestados (Monteiro et al., 1992; Boussim \& Médah, 2009).

Devido a forma como adquirem água e minerais essenciais para a manutenção de sua vida, essas plantas acabam prejudicando o desenvolvimento de sua hospedeira. Os principais prejuízos acarretados pelo desenvolvimento de espécies de Struthanthus são a redução ou o impedimento do desenvolvimento e a redução da produtividade das espécies hospedeiras (Cazetta \& Galetti, 2003; Arruda et al., 2008; Silva et al., 2010; Said et al., 2021).

Apesar de suas ações daninhas, S. marginatus também é considerada planta medicinal (Leitão et al., 2013), tendo seus princípios ativos e suas ações farmacológicas previamente analisadas (Freire et al., 2011). Nesses estudos observou-se que essas plantas, através do haustório, podem absorver não somente elementos essenciais, como também compostos secundários de suas plantas hospedeiras (Martins et al., 2006).

Em razão da necessidade de se controlar o ataque dessas plantas em áreas de fruticultura, de recursos madeireiros e não madeireiros e projetos de arborização (Cazetta \& Galetti, 2003), faz se necessário à aquisição de conhecimentos referentes à germinação de S. marginatus, haja vista que só existe trabalho sobre a germinação dessa espécie em condições de laboratório realizado por Azevedo et al. (2018); em condições naturais, tem-se o trabalho realizado por Venturelli (1981), que observou a germinação de $S$. vulgaris Mart., mas nenhum desses trabalhos apresentou a taxa de sementes germinadas.

\section{Metodologia}

Seleção da matriz dos frutos: os espécimes sobre Casuarina equisetifolia L. (Casuarinaceae) foram escolhidos como matrizes para a coleta dos frutos, devido à sua proximidade ao Laboratório de Botânica da Universidade Estadual do Sudoeste da Bahia (campus de Vitória da Conquista), facilitando as observações fenológicas e a coleta dos frutos. 
Figura 1. Germinação de Struthanthus marginatus (Desr.) G.Don (Loranthaceae) sobre Poincianella pluviosa (DC.) L.P. Queiroz (Fabaceae). A. Ramo com infrutescências; B. Morfologia do fruto; C. Método de plantio; D. Início da germinação (após 4 dias); E. Semente germinada (após 10 dias); F. Plântula com a emissão do primeiro par de folhas (após 20 dias); G. Plântula com segundo par de folhas (após 28 dias); H. Plântula plenamente estabelecida, fixada no hospedeiro com início da emissão das raízes epicorticais (após 34 dias).
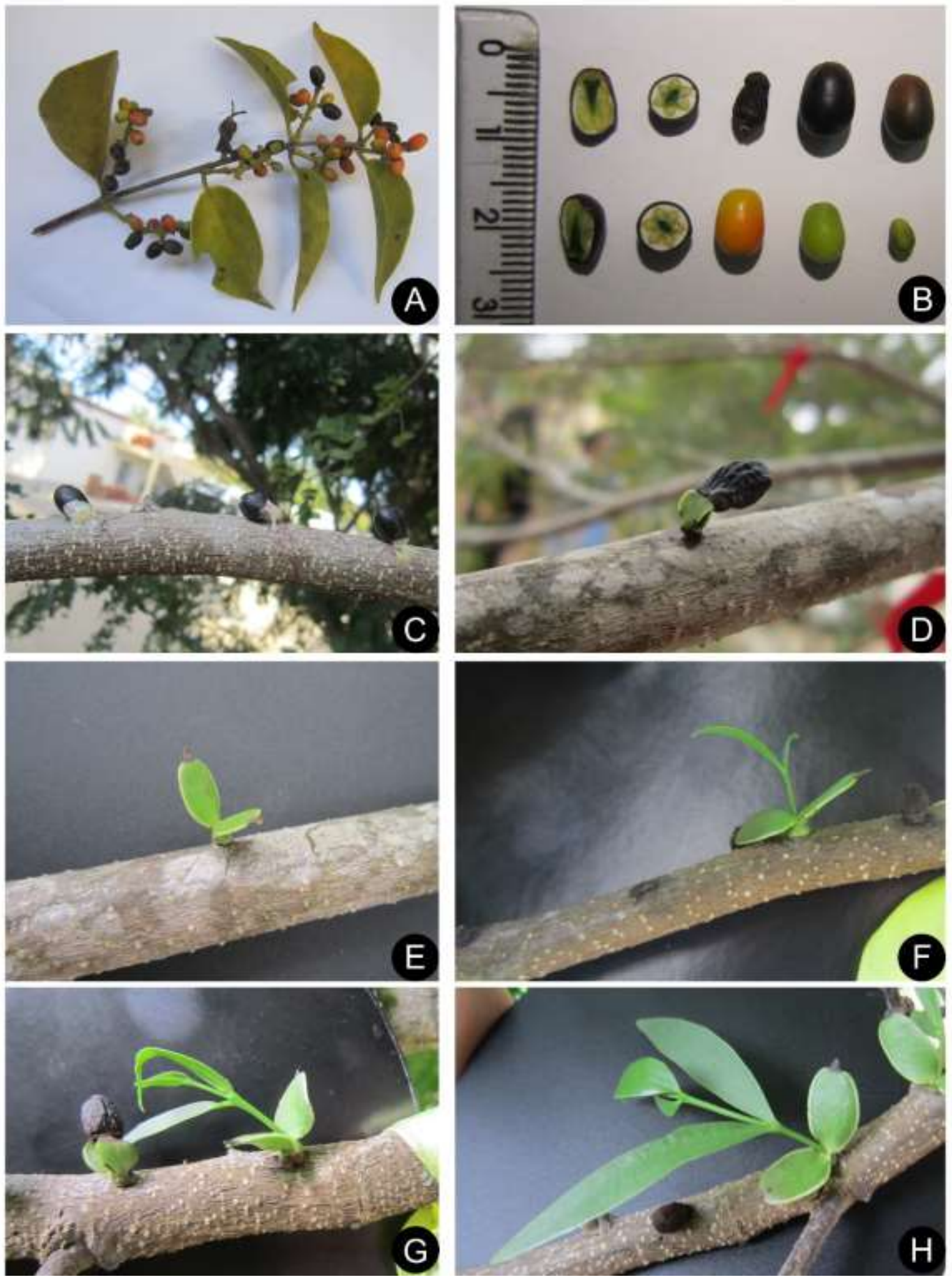

Fonte: Autores. 
Seleção do hospedeiro para plantio: Poincianella pluviosa (DC.) L.P.Queiroz (Fabaceae) foi selecionado como hospedeiro para o plantio devido a sua maior ocorrência no campus (99 indivíduos) contribuindo com a proximidade ao Laboratório de Botânica, além de ser o mais infestado (18 indivíduos) como relatado por Gonçalves e Caires (2015).

Caracterização dos frutos: foram selecionados, aleatoriamente, 50 frutos maduros para a mensuração de sua massa em balança semi-analítica. As dimensões (comprimento $\times$ largura) foram obtidas de 10 frutos com auxílio de régua.

Análise do Teor de Umidade (TU): foram selecionados, aleatoriamente, 50 frutos maduros dos quais se retirou os pericarpos, com o auxílio de uma lâmina de barbear, e se obteve o peso fresco (PF) das sementes e dos pericarpos, separadamente. Após $24 \mathrm{~h}$ em estufa a $85^{\circ} \mathrm{C}$, submeteu-se a mensuração do peso seco (PS) das sementes e dos pericarpos. O cálculo, adaptado de BRASIL (2009), para a determinação do teor de umidade (TU) foi TU = (100.(PF-PS))/PF.

Metodologia de semeadura: o Plantio P1 ( $n=30$ frutos) e o P2 $(n=30$ frutos) foram realizados com a retirada de $1 / 4$ da porção proximal do pericarpo, seguindo a metodologia de Venturelli (1981), onde 30 frutos foram fixados com o auxílio da viscina em três ramos, $10 \mathrm{em}$ cada ramo, selecionados com média de $4 \mathrm{~cm}$ de diâmetro (repetindo o procedimento em P2) (Figura 1C). O P1 foi acompanhado diariamente entre 31 de agosto a 06 de novembro de 2018, enquanto que o P2 foi acompanhado entre os dias 19 de setembro e 06 de novembro de 2018. Os plantios encontravam-se próximos entre si, localizados em ramos baixos em relação ao solo para facilitar o plantio e as observações.

Análise das condições ambientais durante a germinação: os dados meteorológicos foram fornecidos pela Estação Meteorológica da UESB/INMET. Os valores de temperatura média diária do ar (Tmédia/dia) e da umidade relativa diária (UR/dia), foram obtidos pela fórmula $(\mathrm{V} 12 \mathrm{~h}+\mathrm{V} 18 \mathrm{~h}+\mathrm{V} 24 \mathrm{~h}) / 3$, onde $\mathrm{V}=$ refere-se aos valores das temperaturas e das umidades em cada horário, correspondendo, portanto, à média simples diária dos valores mensurados em cada horário (INMET). Além desses valores, a precipitação diária também foi indicada para o período de desenvolvimento das sementes.

Análise das etapas de germinação e estabelecimento da plântula: a semente foi considerada germinada após a emissão da radícula e exposição dos cotilédones; o reconhecimento da espécie hospedeira se considerou após a adesão do disco adesivo ao caule e abertura dos cotilédones; o estabelecimento da plântula foi aceito após a emissão das folhas verdadeiras e do primeiro entrenó.

\section{Resultados e Discussão}

Os frutos de Struthanthus marginatus variaram de $0,75-0,90 \mathrm{~cm}$ de comprimento por $0,41-0,61 \mathrm{~cm}$ de largura nesse estudo, assemelhando-se aos valores encontrados por Azevedo et al. (2018) que foram de $0,75 \mathrm{~cm}$ de comprimento e $0,5 \mathrm{~cm}$ de largura. Venturelli (1981), encontrou valores de 0,80-1,00 cm de comprimento para Struthanthus vulgaris Mart. Comprimentos de frutos de 0,8 cm para Struthanthus flexicaulis (Mart.) Mart. e 0,7 cm para S. andersonii Kuijt, foram obtidos por Kuhlmann (2012), demonstrando similaridade no tamanho dos frutos entre as espécies do gênero, provavelmente associado à dieta alimentar do seu agente dispersor.

A massa dos frutos de S. marginatus, em média, foi de 0,075g. O baixo peso dos frutos contribui para dispersão, por não interferir significativamente no peso das aves, além de obrigarem a ave a se alimentar de inúmeros frutos para a completa saciedade, favorecendo a disseminação das sementes. A alimentação de inúmeros frutos por ave foi observado por Nunes-deAlmeida e Avalos (2016).

Os teores de umidade encontrados para a semente $(58,01 \%)$ e o pericarpo $(48,79 \%)$ de $S$. marginatus demonstram que tanto a semente quanto o pericarpo contribuem para manter o embrião hidratado, haja vista que essas plantas germinam sobre os ramos, longe de fonte de umidade, diferente das demais sementes que retiram sua hidratação do solo. Azevedo et al. (2018), descreveram teores de umidade do fruto de $63,82 \%$, porém no presente estudo o teor de umidade da semente e do pericarpo foram mensurados separadamente. 
No plantio P1 (Tabela 1, Figura 1D) a germinação se iniciou no $16^{\circ}, 17^{\circ}$ e $20^{\circ}$ dias após suas fixações nos ramos um, três e dois, respectivamente. A germinação teve seu pico no vigésimo dia, onde das 30 sementes, $40 \%(\mathrm{n}=12)$ germinaram, $60 \%(\mathrm{n}=18)$ desapareceram do ramo. Dentre as sementes germinadas $92 \%(\mathrm{n}=11)$ morreram e $8 \%(\mathrm{n}=1)$ atingiu o estágio de reconhecimento do hospedeiro.

Os dados climáticos durante o plantio P1 apresentaram a temperatura variando de $16,07-27,17^{\circ} \mathrm{C}$, sendo a média $22,70^{\circ} \mathrm{C}$; a precipitação total foi de $233,2 \mathrm{~mm}^{3}\left(1,90 \mathrm{~mm}^{3}\right.$ até o início da germinação), enquanto a umidade relativa apresentou oscilações entre $52,67-97,33 \%$, sendo a média de $77,02 \%$ de UR/dia.

Tabela 1. Resultado da germinação de Struthanthus marginatus (Loranthaceae) nos três ramos do primeiro plantio.

\begin{tabular}{ccccccc}
\hline Data & \multirow{2}{*}{ Tm( $\left.{ }^{\circ} \mathbf{C}\right)$} & UR(\%) & $\mathbf{P}\left(\mathbf{m m}^{\mathbf{3}}\right)$ & \multicolumn{2}{c}{ Quantidade de sementes germinadas } \\
\cline { 5 - 7 } & & & & Ramo 1 & Ramo 2 & Ramo 3 \\
\hline 31.VIII.2018 & 17,2 & 88,67 & 1,3 & 0 & 0 & 0 \\
16.IX.2018 & 24,57 & 68 & 0,0 & 4 & 1 & 1 \\
19.IX.2018 & 23,7 & 69,67 & 0,0 & 1 & 2 & 1 \\
21.IX.2018 & 24,13 & 68,67 & 0,0 & 1 & 0 & 0 \\
22.IX.2018 & 24,17 & 69,33 & 0,0 & 1 & 0 & 0 \\
06.XI.2018 & 19,77 & 89 & 7,6 & 0 & 0 & 0 \\
Total & - & - & $\mathbf{8 , 9}$ & $\mathbf{7}$ & $\mathbf{3}$ & $\mathbf{2}$ \\
\hline
\end{tabular}

Tm = temperatura média diária; UR = umidade relativa diária; $\mathrm{P}$ = precipitação diária. Fonte: UESB/INMET (dados meteorológicos) e os próprios autores (dados da germinação).

No plantio P2 (Tabela 2, Figura 1C, E-H) a germinação ocorreu após o quinto dia de forma rápida e intensa. O pico germinativo ocorreu seis dias após o plantio, onde das 30 sementes, $80 \%(\mathrm{n}=24)$ germinaram, $10 \%(\mathrm{n}=3)$ desapareceram dos ramos e $10 \%(\mathrm{n}=3)$ morreram. Dentre as sementes germinadas, $50 \%(\mathrm{n}=12)$ morreram após a germinação, $21 \%(\mathrm{n}=5)$ mantiveram-se no estágio inicial de germinação e $29 \%(n=7)$ se estabeleceram atingindo a fase de estabelecimento da plântula.

As condições de temperatura variaram de $16,07-27,17^{\circ} \mathrm{C}$, sendo a média de $23^{\circ} \mathrm{C}$; a precipitação total foi de 187,1 $\mathrm{mm}^{3}$ (com zero de precipitação até o início da germinação) e umidade relativa entre 52,67-97,33\%, sendo a média de 77,89\%.

Analisando o sucesso germinativo nos plantios P1 e P2, temos que das 60 sementes, 60\% $(n=36)$ germinaram, 35\% $(\mathrm{n}=21)$ desapareceram do ramo e $5 \%(\mathrm{n}=3)$ não apresentaram germinação. Dentre todas as sementes germinadas observamos que 64\% ( $\mathrm{n}=23$ ) morreram após a germinação e somente 19\% ( $\mathrm{n}=7)$ atingiram o estágio de estabelecimento de plântula (Figura 1F) e 17\% ( $\mathrm{n}=6$ ) mantiveram-se no estágio inicial de germinação até a sua morte tardia.

A data de início da germinação de P2 coincide com a data de P1, cujo plantio ocorreu dias antes. Notamos que os valores de temperatura (Tmédia/dia), precipitação e umidade relativa (UR/dia), assemelham-se, nos períodos de máxima germinação de P1 e P2, sendo que a temperatura variou de $23,53-24,57^{\circ} \mathrm{C}$, a precipitação total durante esse período foi de zero milímetros cúbicos e a variação da umidade relativa foi de $65-74,67 \%$.

Comparando as condições meteorológicas de temperatura, umidade relativa do ar e precipitação agregados com o sucesso germinativo das sementes de S. marginatus dos plantios 1 e 2, observa-se que não houve influência significativa. Em condições de laboratório, Azevedo et al. (2018), observaram que a germinação de S. marginatus foi acentuada pela retirada do pericarpo e pela temperatura entre $20-30^{\circ} \mathrm{C}$.

Venturelli (1981) observou a germinação de Struthanthus vulgaris em condições naturais. Em seu experimento a 
germinação iniciou-se no quarto dia, com abertura completa dos cotilédones no trigésimo dia. Somente após três meses as primeiras folhas e entrenós começaram a surgir e, somente com seis meses, as raízes epicorticais apareceram. Em nossas observações o início da germinação também ocorreu rápidamente no P2, porém todas as demais etapas do desenvolvimento da plântula se mostraram muito mais rápidas em Struthanthus marginatus do que aquelas observadas em S. vulgaris por Venturelli (1981).

Tabela 2. Resultado da germinação de Struthanthus marginatus (Loranthaceae) nos três ramos do segundo plantio.

\begin{tabular}{ccccccc}
\hline Data & Tm( $\left.{ }^{\circ} \mathbf{C}\right)$ & UR(\%) & P( $\left.\mathbf{m m}^{\mathbf{3}}\right)$ & \multicolumn{2}{c}{ Quantidade de sementes germinadas } \\
\cline { 5 - 6 } & & & & Ramo 1 & Ramo 2 & Ramo 3 \\
\hline 19.IX.2018 & 23,7 & 69,67 & 0 & 0 & 0 & 0 \\
22.IX.2018 & 24,17 & 69,33 & 0 & 5 & 3 & 3 \\
23.IX.2018 & 24,1 & 65 & 0 & 1 & 2 & 3 \\
24.IX.2018 & 22,97 & 67,67 & 0 & 3 & 2 & 1 \\
28.IX.2018 & 24,9 & 59 & 0 & 0 & 1 & 0 \\
06.XI.2018 & 19,77 & 89 & 7,6 & 0 & 0 & 0 \\
Total & - & - & $\mathbf{7 , 6}$ & $\mathbf{9}$ & $\mathbf{8}$ & $\mathbf{7}$ \\
\hline
\end{tabular}

$\mathrm{Tm}$ = temperatura média diária; UR = umidade relativa diária; $\mathrm{P}$ = precipitação diária. Fonte: UESB/INMET (dados meteorológicos) e os próprios autores (dados da germinação).

\section{Considerações Finais}

Os valores semelhantes de comprimento e largura das sementes na espécie analisada no presente estudo e entre àquelas espécies de Struthanthus avaliadas em outros estudos induzem o entendimento de que as espécies atendem aos mesmos agentes dispersores. Observações de Nunes-de-Almeida e Avalos (2016) registraram três espécies de aves consumindo os frutos de Struthanthus marginatus e Snow (2004) registrou esses mesmos grupos de aves consumindo outras espécies de Loranthaceae. A baixa ou a não precipitação não se mostrou um fator limitante para a germinação, visto que os plantios 1 e 2 apresentaram germinação mesmo na ausência de precipitação. Sendo assim, a água contida no fruto e na semente é suficiente para suprir a necessidade do embrião, porém fatores que promovem a dessecação da semente, podem causar alta mortalidade.

Consideramos que o sucesso germinativo de $S$. marginatus na cidade e nas condições analisadas foi maior em ambiente com baixa dessecação, com uma temperatura média diária entre $23,53-24,57^{\circ} \mathrm{C}$, aliada à uma umidade relativa do ar entre 65-74,67\%, encontradas durante o período de 15 a 22 de setembro do ano analisado, período que corresponde a máxima germinação dos plantios. Cabe salientar que podem existir outros fatores influenciadores da germinação, entretanto, o presente estudo limitou-se a observar o período de tempo necessário para a germinação, bem como o sucesso germinativo. Portanto, são necessários novos estudos para verificar os fatores abióticos que teriam maior influência no processo germinativo e os fatores bióticos e/ou abióticos com influência no estabelecimento das plântulas, haja vista que as plântulas já bem estabelecidas no presente estudo acabaram morrendo sem motivo aparente.

\section{Agradecimentos}

À Estação Meteorológica, ao Programa de Iniciação Científica e ao Laboratório de Botânica da Universidade Estadual do Sudoeste da Bahia pelos recursos necessários para o desenvolvimento da pesquisa. Esta é a publicação 14 da série Técnica do Parasitic Plants Research Group. 


\section{Referências}

Arruda, R., Fadini, R. F., Mourão, F. A., Jacobi, C. M., \& Teodoro, G. S. (2008). Natural history and Ecology of Neotropical mistletoes. Encyclopedia of Life Support Systems (EOLSS).

Auer, C. G. (1996). Doenças de árvores urbanas: EMBRAPA/CNPF.

Aukema, J. E., \& Martínez-del-Rio, C. (2002). Where does a fruit-eating bird deposit mistletoe seeds? Seed deposition patterns and an experiment. Ecology, 83(12), 3489-3496.

Azevedo, J. M. L., Santos, C. G. G., Caires, C. S., Araújo-Neto, J. C., \& Souza, R. C. (2018). Morphometry and germination of Passovia pyrifolia, Struthanthus marginatus, and Phoradendron mucronatum diaspores. Planta Daninha, 36, 1-12. 10.1590/S0100-83582018360100010

Boussim, J. I., \& Médah, N. (2009). Méthodes de lutte contre les Loranthaceae. Flora et Vegetatio Sudano-Sambesica, 12 , $27-35$.

BRASIL. (2009). Regras para análise de sementes. Ministério da Agricultura, Pecuária e Abastecimento. Secretaria de Defesa Agropecuária: MAPA/ACS. 399 p.

Caires, C. S., \& Dettke, G. A. (2020). Struthanthus. In Flora do Brasil $2020 . \quad$ Jardim Botânico do Rio de Janeiro. http://floradobrasil.jbrj.gov.br/reflora/floradobrasil/FB8711.

Cazetta, E., \& Galetti, M. (2003). Ecologia das ervas-de-passarinho. Ciência Hoje, 33, $72-74$.

Freire, S. M. F., Andrade, K. N. S., Aragão-Júnior, G. A., Noronha, E. P., Silva, S. N., Cartágenes, M. S. S., Borges, M. O. R., Ribeiro, M. N. S., Torres, L. M. B., \& Borges, A. C. R. (2011). Antiulcerogenic activity of the extracts of Struthanthus marginatus. Revista Brasileira de Farmacognosia, $21(6), 1089-1095$. $10.1590 / \mathrm{S} 0102-695 \mathrm{X} 2011005000150$

Gonçalves, K. M., \& Caires, C. S. (2015). Distribuição espacial da arborização da Universidade Estadual do Sudoeste da Bahia, Campus Vitória da Conquista, como método para inventário das ervas-de-passarinho. In: XIX Seminário de Iniciação Científica e Tecnológica da UESB, 2015, Vitória da Conquista. Anais [...]. Vitória da Conquista: UESB, 282-285.

Leitão, F., Leitão, S. G., Almeida, M. Z., Cantos, J., Coelho, T., \& Silva, P. E. A. (2013). Medicinal plants from open-air markets in the State of Rio de Janeiro, Brazil as a potencial source of new antimycobacterial agents. Journal of Ethnopharmacology, 149(2), 513-521. 10.1016/j.jep.2013.07.009

Martins, L. G. S., Vale, L. S., Lainetti, R., \& Pereira, N. A. (2006). Um estudo sobre a toxicidade da erva-de-passarinho (Struthanthus marginatus, Loranthaceae), parasitando trombeteira (Datura suaveolens, Solanaceae). Revista Brasileira de Farmácia, 87(2), 63-64.

Monteiro, R. F., Martins, R. P., \& Yamamoto, K. (1992). Host specificity and seed dispersal of Psittacanthus robustus (Loranthaceae) in South-east Brazil. Journal of Tropical Ecology, 8(3), 307-314. 10.1017/S026646740000657X

Nunes-de-Almeida, C. H. L., \& Avalos, V. R. (2016). Foraging techniques of Swallow-tailed Cotinga (Phibalura flavirostris) on fruits of Struthanthus marginatus (Loranthaceae) in Monte Verde, Camanducaia, state of Minas Gerais, Brazil. Revista Brasileira de Ornitologia, 24(1), 27-29.

Rotta, E. (2001). Ervas-de-passarinho (Loranthaceae) na Arborização Urbana: passeio público de Curitiba, um estudo de caso. Tese [Doutorado em Ciências Florestais] - Universidade Federal do Paraná, Curitiba.

Said, M. M., Rivas, A. A. F., \& Oliveira, L. A. (2021). Cupuassu plant mangement and the market situation of Itacoatiara, Manacapuru and Presidente Figueiredo counties, Amazonas State, Brazil. Research, Society and Development, 10(3), e15110313109. 10.33448/rsd-v10i3.13109

Silva, F. N. S., Conceição, G. M., \& Almeida, D. B. (2010). Ocorrência da família Loranthaceae no município de Caxias, Maranhão, Brasil. Cadernos de Geociências, 7(2), 131-135.

Snow, D. W. (2004). Family Cotingidae (cotingas), p. 32-66. In: del Hoyo, J., Elliott, A., \& Christie, D. (eds.). Handbook of the birds of the world. 9: Cotingas to pipits and wagtails. Barcelona Lynx Edicions.

Venturelli, M. (1980). Estudos morfo-anatômicos e ontogenéticos em Struthanthus vulgaris Mart. (Loranthaceae - Loranthoideae) e de seu relacionamento com o hospedeiro. Tese [Doutorado em Ciências] - Universidade de São Paulo, São Paulo.

Venturelli, M. (1981). Estudos sobre Struthanthus vulgaris Mart.: anatomia do fruto e semente e aspectos de germinação, crescimento e desenvolvimento. Revista Brasileira de Botânica, 4(2), 131-147. 